\title{
In Vitro Analysis of Chemotactic Leukocyte Migration in 3D Environments
}

\author{
Michael Sixt and Tim Lämmermann
}

\begin{abstract}
Cell migration on two-dimensional (2D) substrates follows entirely different rules than cell migration in three-dimensional (3D) environments. This is especially relevant for leukocytes that are able to migrate in the absence of adhesion receptors within the confined geometry of artificial 3D extracellular matrix scaffolds and within the interstitial space in vivo. Here, we describe in detail a simple and economical protocol to visualize dendritic cell migration in $3 \mathrm{D}$ collagen scaffolds along chemotactic gradients. This method can be adapted to other cell types and may serve as a physiologically relevant paradigm for the directed locomotion of most amoeboid cells.
\end{abstract}

Key words: 3D, Interstitial migration, Chemotaxis, Chemokine gradient, Cell motility, Collagen, Extracellular matrix, Interstitium, Connective tissue

\section{Introduction}

Stromal cells, together with their secreted extracellular matrix, constitute the structural and mechanical backbone of most organs. Collagen type I has been widely used to re-create three-dimensional (3D) networks for the in vitro study of organogenesis, vessel development, fibril assembly, fibroblast mechanics, cell polarity, tumor metastasis, and leukocyte migration (1-7). Although other $3 \mathrm{D}$ in vitro systems exist (with Matrigel and fibrin gels as the next most common), 3D collagen I gels most closely resemble the in vivo interstitial matrix in connective tissues as collagen $I$ is the major constituent of most interstitial tissues (4). Importantly, it is becoming increasingly evident that cell migration analysis in $3 \mathrm{D}$ 
systems reflects physiological cell behavior much better than results obtained from $2 \mathrm{D}$ in vitro systems (e.g., cell culture dish) $(2,5,8-10)$. The physical nature of collagen gels (density, pore size, stiffness, and bundle thickness) is highly dependent on the initial collagen source and extraction process (4). Most commonly, $3 \mathrm{D}$ in vitro collagen models are based on rat-tail or bovine dermis collagen, which differ in their chemical cross-linking, extraction protocol, and fiber assembly, leading to discrepancies in experimental outcome $(4,11)$.

Migrating cells are characterized by their polarized appearance with a leading and a trailing edge. Cells either undergo spontaneous polarization or polarize in response to gradients of chemokines, cytokines, growth factors, or extracellular matrix fragments. In connective tissues, directional migration toward a chemotactic source has been observed for neutrophils, monocytes (toward sites of inflammation and tissue injury) (12), dendritic cells, and tumor cells (toward lymphatic vessels) $(2,13,14)$. Cells chemotaxing in fibrillar 3D networks face different challenges than in 2D systems. Apart from polarizing, they also have to maintain integrity while navigating through a geometrically complex porous environment $(7,15)$. While the 3D chemotaxis assays can be studied in collagen gel-coated transwells, this experimental system is restricted to endpoint analysis and it is not trivial to differentiate between a general cell motility response to a chemokine (chemokinesis) and true directional migration (chemotaxis). Time-lapse video microscopy overcomes these limitations and allows direct analysis of parameters such as directionality (chemotactic index) and cell velocity. Simple cell culture bright-field microscopes equipped with a heating chamber and triggered by software are sufficient to record low magnification movies and determine chemotactic parameters $(2,8)$. For more detailed analysis of moving cells in the context of their fibrillar environment, both polarized cells and collagen fibers can be visualized in high magnification with different kinds of microscopy (Table 3$)(2,4,9,16)$.

We provide here a simple method for visualizing chemotaxis of cells in 3D bovine collagen gels by time-lapse video brightfield-microscopy and analysis of cell velocity and directionality. This experimental setup can also be extended to the study of polarized cells and cell-collagen matrix interactions with confocal microscopy. Our primary intention here is to describe a method that can be quickly established in almost every laboratory without the acquisition of extremely specialized or costly materials, reagents, or instruments. 3D assay systems that include other tissue parameters such as lymphatic flow in connective tissues have been detailed elsewhere $(14,17)$. 


\section{Materials}

\subsection{Cell Culture}

2.2. Paraffin Mix

\subsection{Standard Migration Chamber}

\subsection{Collagen Network and Chemokine Gradient}

1. Murine long bones (femurs).

2. One pair of standard forceps (curved or straight, with serrated tips).

3. One pair of scissors (straight, small).

4. Petri dishes (sterile, $100 \times 15 \mathrm{~mm}$ ).

5. Tissue-culture dishes (sterile, $60 \times 15 \mathrm{~mm}$ ).

6. R10 medium: Heat-inactivate fetal calf serum (FCS) or fetal bovine serum (FBS) in a $56^{\circ} \mathrm{C}$ water bath for $30 \mathrm{~min}$ and then sterile-filter it $(0.22 \mu \mathrm{m})$. Rl0 medium is RPMI- 1640 supplemented with $2 \mathrm{mM}$ L-glutamine, $100 \mathrm{U} / \mathrm{mL}$ penicillin, $100 \mu \mathrm{g} / \mathrm{mL}$ streptomycin, and heat-inactivated, filtered FCS or FBS (10\%) (see Note 1).

7. Plastic syringes (sterile, $20 \mathrm{~mL}$ ).

8. Needles (sterile, 23G 1" or 25G 1").

9. LPS solution: Lipopolysaccharides from Escherichia coli 0127:B8 (suitable for cell culture, $\gamma$-irradiated, Sigma, St. Louis, MO). Prepare a $1 \mathrm{mg} / \mathrm{mL}$ solution in sterile phosphate-buffered saline (PBS) and freeze aliquots at $-20^{\circ} \mathrm{C}$ (see Note 2 ).

10. GM-CSF solution: Recombinant murine granulocyte macrophage-colony stimulating factor (GM-CSF). Prepare a $50 \mu \mathrm{g} / \mathrm{mL}$ solution in sterile water and freeze aliquots at $-80^{\circ} \mathrm{C}$.

11. Polypropylene conical centrifuge tube $(50 \mathrm{~mL})$.

1. Paraffin: paraffin wax $\left(\mathrm{mp}>60^{\circ} \mathrm{C}\right)$ or paraffin pellets.

2. Petroleum jelly (e.g., Vaseline).

3. Laboratory hot plate.

1. Microscopy glass slides (microslides, $75 \times 25 \mathrm{~mm}$ ). As an alternative you can use glass-bottom culture dishes $(35 \mathrm{~mm}$, 7-14 mm glass, No. 1.5 thickness) (MatTek, Ashland, MA).

2. One paint brush (brush size: 6-12, flat or round brush, any bristle material will work).

3. Microscope cover glasses $(18 \times 18 \mathrm{~mm}$, No. 1.5 thickness $)$.

1. Bovine collagen solution: Purecol ${ }^{\circledR}(3 \mathrm{mg} / \mathrm{mL})$ or Nutragen ${ }^{\circledR}$ $(6 \mathrm{mg} / \mathrm{mL})$ (both Advanced Biomatrix, CA). Both collagen preparations are soluble atelo-collagen in $0.01 \mathrm{~N} \mathrm{HCl}$; therefore, the $\mathrm{pH}$ is ca. 2.0 (see Note 3 ), store at $4^{\circ} \mathrm{C}$.

2. Sodium bicarbonate solution $\left(\mathrm{NaHCO}_{3}, 7.5 \%\right.$, Sigma, St. Louis, $\mathrm{MO})$, sterile-filtered, cell culture tested, store at $4^{\circ} \mathrm{C}$. 
2.5. Bright-Field Video Microscopy

\subsection{Analysis of Dendritic Cell Chemotaxis with ImageJ}

\subsection{Preparing}

Fluorescent Collagen
3. Minimal essential medium (Eagle) $(10 \times$, Sigma), with Earle's salts, without L-glutamine and sodium bicarbonate, liquid, sterile-filtered, cell culture tested, store at $4^{\circ} \mathrm{C}$.

4. Plastic microslide box (to hold $75 \times 25 \mathrm{~mm}$ microslides, as used for histology samples).

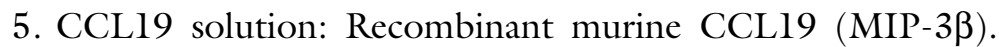
Prepare a $25 \mu \mathrm{g} / \mathrm{mL}$ solution in sterile PBS and $1 \mathrm{mg} / \mathrm{mL}$ bovine serum albumin (BSA) and store aliquots at $-20^{\circ} \mathrm{C}$.

For low magnification bright-field movies, any standard bright-field microscopy setup with a heated microscopy stage, $10 \times$ or $20 \times$ objective, camera, and software-triggered recording will be suitable.

Our experimental setup comprised an inverted Axiovert 40 (Zeiss) cell culture microscope, equipped with custom-built climate chambers $\left(5 \% \mathrm{CO}_{2}, 37^{\circ} \mathrm{C}\right.$, humidified) and PAL cameras (Prosilica) triggered by custom-made software (SVS Vistek). For parallel recording of several experiments, we ran one experiment at one of three microscopes simultaneously. Other microscopes are available which allow several experiments to run simultaneously by recording multiple stage positions at defined time intervals.

1. ImageJ free software (http://rsbweb.nih.gov/ij/, National Institutes of Health, Bethesda, MD).

2. Image J plugins: Manual Tracking, Chemotaxis, and Migration Tool (http://rsbweb.nih.gov/ij/plugins).

1. Alexa Fluor 647 carboxylic acid, succinimidyl ester (A-20006, Invitrogen).

2. Dimethyl sulfoxide (DMSO).

3. Dialysis solution: Add $1.15 \mathrm{~mL}$ glacial acetic acid $(17.4 \mathrm{~N})$ to $999 \mathrm{~mL}$ distilled water to create glacial acetic acid of $0.02 \mathrm{~N}$ and $\mathrm{pH} 3.9$.

4. Dialysis tubing (molecular weight cut off (MWCO) 3,500 Da).

5. Two dialysis clamps.

\section{Methods}

The whole procedure is comprised of four principal steps: (1) Construction of a migration chamber (which can be done on the day before the experiment), (2) casting a collagen gel matrix containing cells (which takes ca. 45-60 min), (3) application of a chemotactic gradient and subsequent time-lapse video microscopy, and (4) analysis of the imaging data with ImageJ software. 
This method is not limited to bright-field microscopy only, but can also be used to visualize chemotactic cells in the context of their fibrillar environment with different kinds of confocal microscopy at high magnification and resolution. Table 3 summarizes the common techniques used to visualize collagen networks and we describe in Subheading 3.10 how to generate fluorescent collagen gels. Although this method is potentially applicable to any chemotactic cell type, we will describe a protocol for the generation of dendritic cells from murine bone marrow (18). Dendritic cell migration toward the chemokine CCL19 shows very robust directional migration over several hours and can be used as a positive control to test other $3 \mathrm{D}$ chemotaxis setups $(2,8)$.

3.1. Generation of Primary Dendritic Cells from Murine Bone Marrow
1. Euthanize the mouse according to your animal study protocol and local regulations.

2. Dissect the mouse and carefully remove the legs from the pelvic bone without destroying the head of the femur. The femur and tibia can be separated by cutting the knee ligaments with scissors. Once separated, rub the muscles gently off the femoral bone with utility wipes. Place the muscle-free femurs in a Petri dish with $70 \%$ ethanol and continue your work in a biological safety cabinet.

3. Immerse the femurs in $70 \%$ ethanol for $1 \mathrm{~min}$ and let them air-dry in a new Petri dish. With sterile forceps and scissors (e.g., incubated in 70\% ethanol before), pick up the femur in the middle of the shaft with the forceps and cut off both ends with the scissors.

4. Hold the femur (with the forceps) over a centrifuge tube and flush out the red marrow with sterile PBS, using a syringe and a needle. The marrow will appear as a red strand in the tube and the cavity of the femur will turn from red to white color.

5. Centrifuge the resultant cell suspension for $5 \mathrm{~min}$ at $300 \times \mathfrak{g}$ $\left(4-20^{\circ} \mathrm{C}\right)$.

6. Discard supernatant and take the cell pellet up in Rl0 medium, then adjust the cell concentration to $2.5 \times 10^{6}$ cells $/ \mathrm{mL}$.

7. For each Petri dish, use $1 \mathrm{~mL}$ bone marrow-cell suspension to $9 \mathrm{~mL}$ Rl0 medium, then add $4 \mu \mathrm{L}$ GM-CSF solution to a final concentration of $20 \mathrm{ng} / \mathrm{mL}$ GM-CSF. Incubate the cells at $37^{\circ} \mathrm{C}, 5 \% \mathrm{CO}_{2}, 95 \% \mathrm{H}_{2} \mathrm{O}$. This is the start day of the dendritic cell culture (day 0 ).

8. Three days later (day 3 ), add $10 \mathrm{~mL} \mathrm{Rl0} \mathrm{medium} \mathrm{and} 4 \mu \mathrm{L}$ GM-CSF solution.

9. Three days later (day 6), carefully remove $10 \mathrm{~mL}$ of the medium and add again $10 \mathrm{~mL} \mathrm{R10}$ medium and $4 \mu \mathrm{L}$ GM-CSF solution. Until days 8-9, the culture is highly enriched for immature dendritic cells. 


\subsection{Preparation of the "Paraffin Mix"}

3.3. Preparation of the "Standard Migration Chamber"

\subsection{Preparation of the Cell Suspension}

10. At days 8-9 of culture, collect the medium and non-adherent cells in suspension in a centrifuge tube and centrifuge the cells for $5 \mathrm{~min}$ at $300 \times g\left(4-20^{\circ} \mathrm{C}\right)$.

11. Discard the supernatant and take up the cell pellet of one Petri dish $(100 \times 15 \mathrm{~mm})$ in $10 \mathrm{~mL}$ R10 medium. Transfer this cell suspension to one tissue-culture dish $(60 \times 15 \mathrm{~mm})$ and add $4 \mu \mathrm{L}$ GM-CSF solution. The adhesive surface of the tissue-culture dish will further separate adherent immature dendritic cells and remnant macrophages from non-adherent mature dendritic cells.

12. To induce maturation of dendritic cells, add $2 \mu \mathrm{L}$ LPS solution to the tissue-culture dish. After $24-36 \mathrm{~h}$ of incubation at $37^{\circ} \mathrm{C}$, $5 \% \mathrm{CO}_{2}, 95 \% \mathrm{H}_{2} \mathrm{O}$, mature dendritic cells have a characteristic morphology (Fig. 3a, see Notes 1 and 2). Do not use dendritic cells at time points later than $36 \mathrm{~h}$ after LPS stimulation, as they then undergo apoptosis.

1. Heat paraffin wax or pellets at $60-80^{\circ} \mathrm{C} / 140-178^{\circ} \mathrm{F}$ in a small beaker (100 mL size) on a hot plate until the paraffin is fluid.

2. Prepare the paraffin mix by adding petroleum jelly to the fluid paraffin in a $1: 3-1: 5$ ratio by volume (see Note 4 ).

1. Take a glass slide (or glass-bottomed microscopy dish, see Note 5 ) (Fig. la).

2. Take the brush, dip it into the paraffin mix, and paint a "squared U" (ca. $20 \times 20 \mathrm{~mm}$ ) with the paraffin in the center of the glass slide (Fig. 1b). The paraffin will quickly become solid on the colder glass slide. The paraffin line should be ca. $3-5 \mathrm{~mm}$ in width. Repeat this step 2-3 times until the paraffin line is approximately $1-\mathrm{mm}$ thick in height.

3. Take the coverslip $(18 \times 18 \mathrm{~mm})$ and lay it on top of the "squared U"-paraffin line (Fig. 1c).

4. Fix the coverslip with your fingers and brush a layer of paraffin mix over the border of the coverslip. The coverslip should be sealed between the paraffin lines providing a migration chamber that can be filled from its open top (Fig. Id).

1. After 24-36 h of stimulation of dendritic cells with LPS, take off the supernatant from the $6-\mathrm{cm}$ cell culture dish (collect the non-adherent mature dendritic cells) and transfer it to a 50-mL plastic tube. You might have to pool cells from several dishes.

2. Centrifuge the cell suspension for $5 \mathrm{~min}$ at $300 \times g\left(4-20^{\circ} \mathrm{C}\right)$.

3. Discard the supernatant and take the cell pellet up in $1 \mathrm{~mL}$ Rl0 medium. 

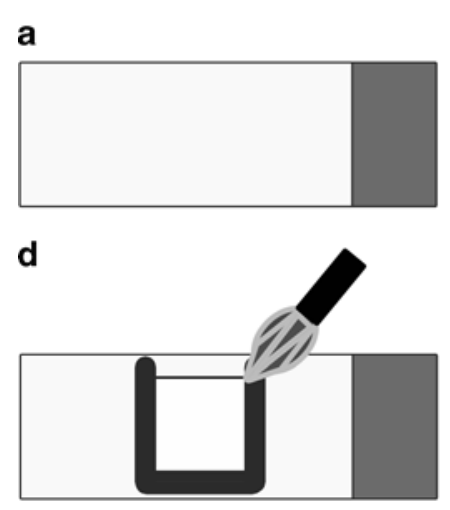

g collagen-cell-mix
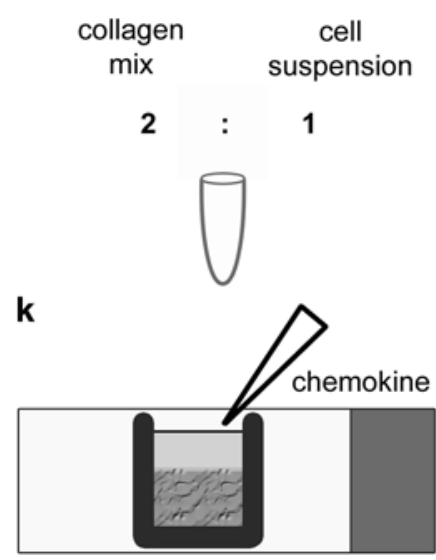

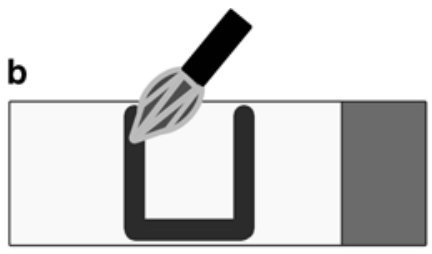

e

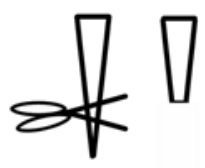

h
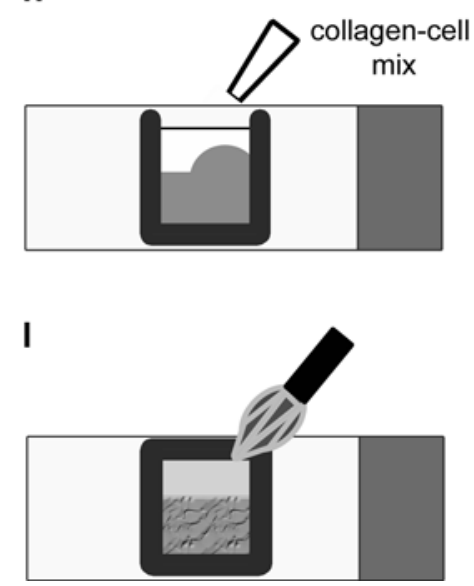

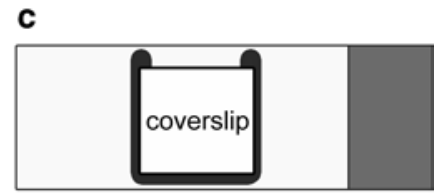

f collagen-mix

$\mathrm{NaHCO}_{3}$ MEM(10X) collagen

$1: 2: 15$

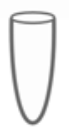

i

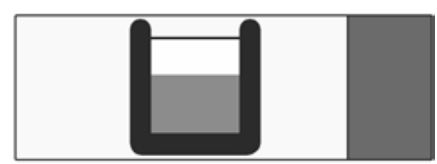

Fig. 1. General scheme (for detailed instructions, please see Subheadings 3.2-3.8). (a-d), building the migration chamber; (e-i), casting the 3D collagen gel; ( $\mathbf{k}$ and I), application of the chemokine gradient.

\subsection{Preparation} of the "Collagen Mix"

\subsection{Preparation of the} "Collagen-Cell Mix"
4. Count the cell number and then adjust the cell concentration to $3 \times 10^{6}$ cells $/ \mathrm{mL}$ with Rl0 medium (see Note 6 ).

5. Keep the cell suspension at $37^{\circ} \mathrm{C}, 5 \% \mathrm{CO}_{2}$ (before continuing with it in Subheading 3.6) (see Note 7).

1. Take a $1.5-\mathrm{mL}$ reaction tube.

2. Cut off one-third of some pipette tips (Fig. le, see Note 8).

3. For a standard collagen gel of $1.7 \mathrm{mg} / \mathrm{mL}$, prepare a collagen mix of sodium bicarbonate, $\operatorname{MEM}(10 \times)$, and Purecol $^{\circledR}(3 \mathrm{mg} / \mathrm{mL})$ in a 1:2:15 ratio (Fig. If, see Note 9). Calculate $100 \mu \mathrm{L}$ of collagen mix for one standard migration chamber, although less is actually needed (Tables 1 and 2, see Note 10).

1. Take a $1.5-\mathrm{mL}$ reaction tube.

2. Cut off one-third of some pipette tips. 


\section{Table 1}

\section{Pipetting scheme for the "collagen mix"}

\begin{tabular}{lllllll} 
Sample number & & $\mathbf{1}$ & $\mathbf{1 0}$ & & $\mathbf{1}$ & 10 \\
\hline Collagen $^{\mathrm{a}}(\mu \mathrm{L})$ & $75(\mathrm{P})$ & $83.3(\mathrm{P})$ & $833(\mathrm{P})$ & $75(\mathrm{~N})$ & $83.3(\mathrm{~N})$ & $833(\mathrm{~N})$ \\
\hline MEM $(10 \times)(\mu \mathrm{L})$ & 10 & 11.1 & 111 & 10 & 11.1 & 111 \\
\hline $\mathrm{NaHCO}_{3}(7.5 \%)(\mu \mathrm{L})$ & 5 & 5.6 & 56 & 5 & 5.6 & 56 \\
\hline $\begin{array}{c}\text { Final volume of "Collagen } \\
\text { mix" }(\mu \mathrm{L})\end{array}$ & 90 & 100 & 1,000 & 90 & 100 & 1,000 \\
\hline $\begin{array}{c}\text { Collagen conc. in "Collagen } \\
\text { mix" }(\mathrm{mg} / \mathrm{mL})\end{array}$ & $2.5(\mathrm{P})$ & $2.5(\mathrm{P})$ & $2.5(\mathrm{P})$ & $5(\mathrm{~N})$ & $5(\mathrm{~N})$ & $5(\mathrm{~N})$ \\
\hline
\end{tabular}

${ }^{\mathrm{a}} \mathrm{P}=$ Purecol, $\mathrm{N}=$ Nutragen

\section{Table 2}

\section{Pipetting scheme for "collagen-cell mix"}

\begin{tabular}{|c|c|c|c|c|c|c|}
\hline Sample number & 1 & 10 & 1 & 10 & 1 & 10 \\
\hline $\begin{array}{l}\text { Collagen conc. in "Collagen } \\
\text { mix" }(\mathrm{mg} / \mathrm{mL})\end{array}$ & $2.5(\mathrm{P})$ & $2.5(\mathrm{P})$ & $2.5(\mathrm{P})$ & $2.5(\mathrm{P})$ & $5(\mathrm{~N})$ & $5(\mathrm{~N})$ \\
\hline "Collagen mix" $(\mu \mathrm{L})$ & 90 & 900 & 100 & 1,000 & 90 & 900 \\
\hline Cell suspension $(\mu \mathrm{L})$ & 50 & 50 & 50 & 500 & 50 & 50 \\
\hline R10 medium $(\mu \mathrm{L})$ & 10 & 10 & - & - & 10 & 10 \\
\hline $\begin{array}{l}\text { Final volume of "Collagen-cell } \\
\text { mix" }(\mu \mathrm{L})\end{array}$ & 150 & 1,500 & 150 & 1,500 & 150 & 1,500 \\
\hline $\begin{array}{l}\text { Final Collagen conc. in } \\
\text { "Collagen-cell mix" } \\
(\mathrm{mg} / \mathrm{mL})\end{array}$ & 1.5 & 1.5 & 1.7 & 1.7 & 3 & 3 \\
\hline
\end{tabular}

3. For a standard collagen gel of $1.7 \mathrm{mg} / \mathrm{mL}$, prepare a collagencell mix of collagen mix and cell suspension $(3 \mathrm{mg} / \mathrm{mL})$ in a 2:1 ratio (Fig. $\mathrm{lg}$ ) (see Note 11 ). Make up $150 \mu \mathrm{L}$ of collagen-cell mix for one standard migration chamber, although less is actually needed (Table 2).

3.7. Polymerization of the Collagen Network (Filled with Cells)
1. Cut off one-third of some pipette tips (as described in Subheading 3.4) and use in the following steps.

2. Place the migration chamber (from Subheading 3.3) upright in a slide holder box. 


\subsection{Application of the Chemokine Gradient and Time- Lapse Video Microscopy}

\subsection{Analysis of Dendritic Cell Chemotaxis with ImageJ}

3. Fill two-thirds of the migration chamber by pipetting the collagen-cell mixture from the upper open side of the chamber and let the mixture drop into the chamber by gravity (Fig. Ih).

4. If the collagen-gel mix does not immediately form an even horizontal lining, then take the migration chamber out of the slide holder, tap it several times gently on the bench, and then put it back into the slide holder (see Note 12).

5. Put the slide holder (with migration chamber(s)) in an incubator at $37^{\circ} \mathrm{C}, 5 \% \mathrm{CO}_{2}$ for at least $30 \mathrm{~min}$ for gel polymerization (Fig. li, see Note 13).

1. Dilute the CCL19 stock concentration in Rl0 medium to a concentration of 50-500 ng/mL. You will require ca. $50 \mu \mathrm{L}$ for one standard migration chamber.

2. Take the slide holder (with the migration chamber(s)) out of the incubator.

3. Fill the empty, upper one-third of the migration chamber with the CCL19 dilution $(50-500 \mathrm{ng} / \mathrm{mL}$ ) laying it on top of the collagen-cell mixture (Fig. lk). The diluted chemokine will diffuse quickly into the gel forming a chemotactic gradient within 5-30 min.

4. Seal the open upper end of the migration chamber with the paraffin mix. The migration chamber represents a closed system (Fig. 11, see Note 14).

5. Start the time-lapse video microscopy soon after applying the chemokine solution. With high chemokine concentrations, the first chemotactic response of dendritic cells can be seen within few minutes at the collagen gel-medium interface.

6. The resultant CCL19 gradient is reasonably stable over time and the dendritic cells directionally migrate toward the chemotactic source for a number of hours. For standard chemotaxis analysis, we employed time-lapse video microscopy with an inverted bright-field microscope, $10 \times$ objective, one frame per minute over 3-4 h (see Notes 15 and 16).

This section outlines the minimal requirements for analyzing 3D collagen chemotaxis with the free online software Image J that is accessible to everyone. This method allows manual tracking of individual chemotactic cells and is sufficient to determine the basic chemotactic parameters (velocity and directionality) (see Note 17). This analysis method requires two additional plugins (Manual Tracking, Chemotaxis, and Migration Tool) that can also be downloaded from the ImageJ homepage (http://rsbweb. nih.gov/ij/plugins). Several data types of the initial time-lapse image sequence can be analyzed; we will describe the analysis of a sequence of .tiff files. 

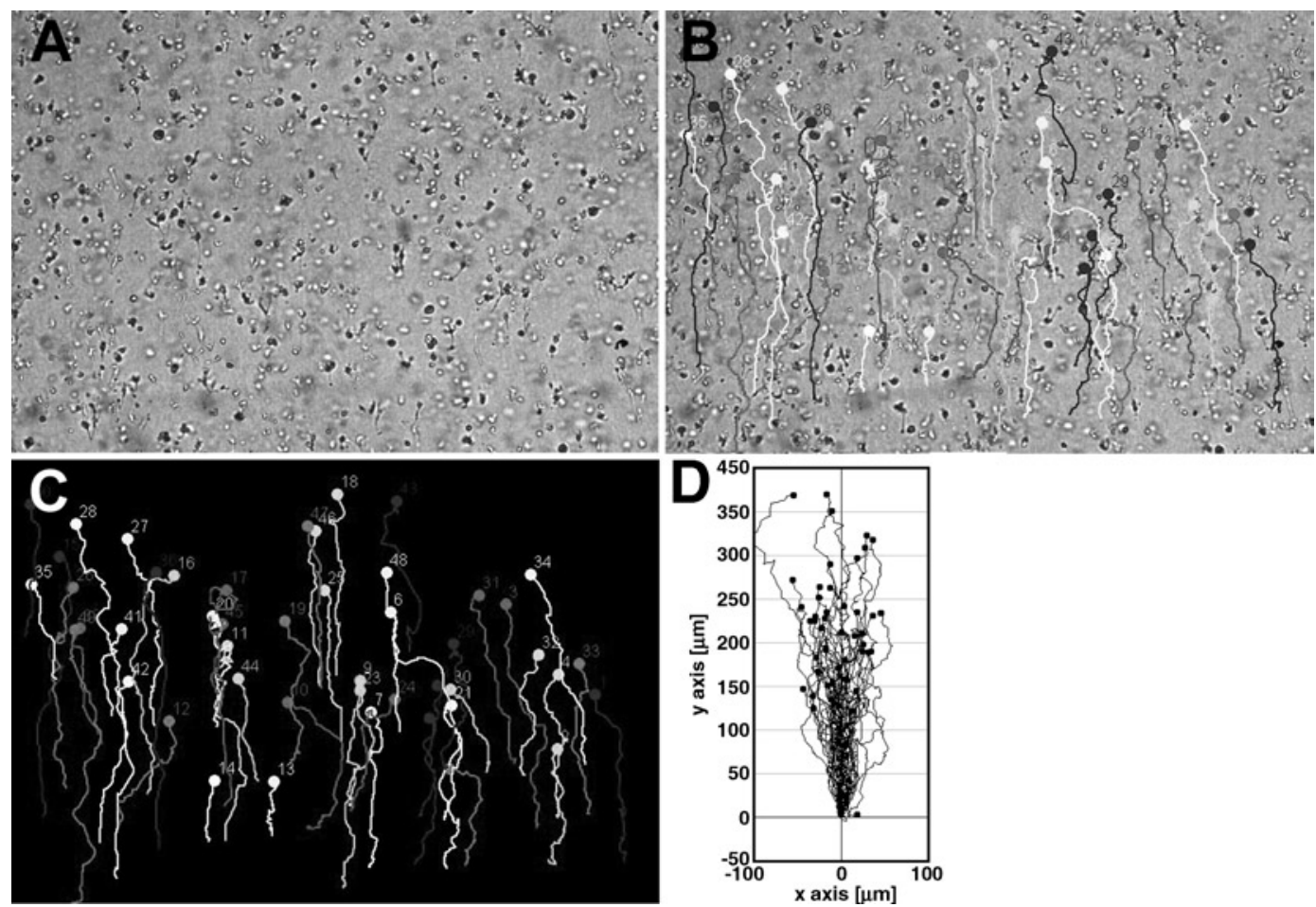

Fig. 2. Chemotaxis analysis with ImageJ (for detailed instructions on how to use ImageJ, please see Subheading 3.9). (a), original image stack; (b), image stack overlaid with cell tracks (overlay dots and lines); (c), cell tracks only (dots and lines); (d) chemotaxis plot graph.

1. Open ImageJ and import your time-lapse image sequence (File - Import - Image Sequence).

2. Under "sequence options," choose the details of your data set to be analyzed, which includes number of images, starting image, and image increment. This will then display the image sequence as image stack (Fig. 2a) that can be animated (Image - Stacks - Start Animation).

3. Open the Manual Tracking plugin. The commands (4 and 5) are performed in the Manual Tracking plugin window.

4. Select "add track," choose one chemotaxing cell and follow its track by clicking into the image stack (one click per frame). The track will either finish automatically when you reached the last frame or you click "end track" before (e.g., when a cell moves out of the field of view). Then choose the next cell and continue as before. All tracks will automatically be numbered. The coordinates for every single click are the basis for the resulting track and calculated parameters. They are automatically recorded as a .txt file which must be stored at the end of the tracking. Saved .txt files can be loaded at any time with "Load Previous Track File." 
5. If you want to display the resultant tracks of several cells, you can choose between different options. Figure 2 b shows "overlay dots and lines," and Fig. 2c shows "dots and lines" of the image stack.

6. Open the Chemotaxis and Migration Tool plugin. All the following commands are operated in this box.

7. Select "Import data" and choose your saved .txt file. Under "number of slices," select "Use slice range from ... to ...," type the first and last number of your image stack, and then select "add dataset."

8. Check one "selected dataset." You can analyze up to four data sets at once.

9. Under "settings," set your X/Y calibration and time interval. All further parameters will be calculated by the numbers and units that are selected here.

10. Then "Apply settings."

11. When choosing "Show Info," you will immediately get different calculated average parameters that also include directionality (value $0-1$, whereby 1 corresponds to chemotaxis along a straight line toward the chemotactic source) and velocity (speed).

12. For obtaining graphic data, we prefer to present chemotaxis data as a plot graph (Fig. 2d). Therefore, select "plot feature," then check "open in new window" and select "plot graph."

13. To adjust the size of the graph, go to "set axis scaling" and select "manual" for your preferred axis lengths. Then select "plot graph" again. This graph can be saved as .jpg or .tiff file when choosing "save as" in the ImageJ toolbar.

3.10. Labeling

Collagen with a Fluorescent Dye
To study moving cells in their fibrillar environment, collagen networks can be visualized by several technical means (see Note 18, Fig. 3b-f, Table 3). While differential interference contrast (DIC) and confocal reflection microscopy make use of the physical properties of unlabeled collagen fibers, confocal laser scanning and spinning-disc microscopy on fluorescent collagen gels provide some other advantages. The pros and cons of the three methods are listed in Table 3. To generate fluorescent collagen, any fluorescent reactive dye can be coupled to pure collagen. Here, we describe collagen labeling with Alexa Fluor 647 carboxylic acid, adapted from the suggested manufacturer protocol.

1. Dissolve $5 \mathrm{mg}$ of Alexa Fluor 647 dye into $0.5 \mathrm{~mL}$ DMSO. As the reactive compounds of the dye are not stable in solution, dissolve the dye immediately before starting the labeling solution.

2. Place $10 \mathrm{~mL}$ of Purecol ${ }^{\circledR}$ in a small beaker with a stir bar and slowly stir it on a magnetic plate. Slowly add $100 \mu \mathrm{L}$ of the 

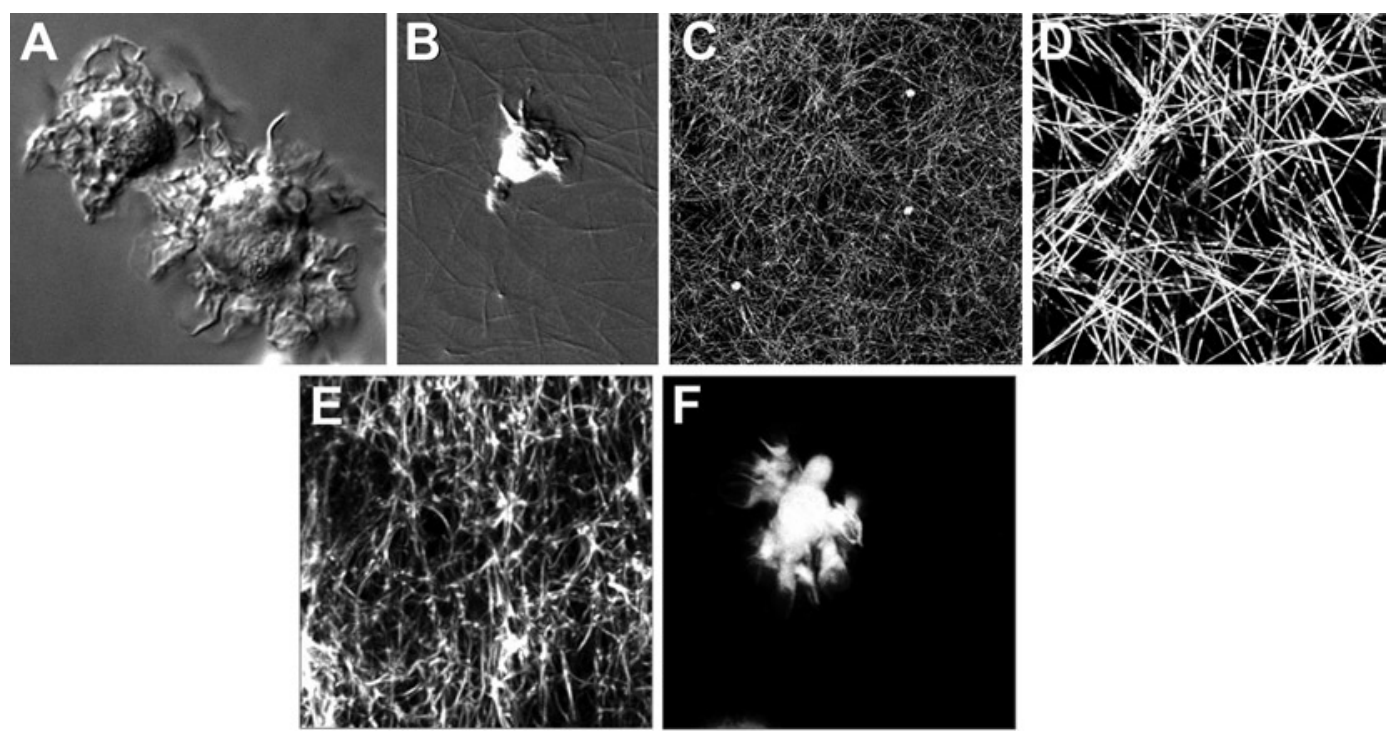

Fig. 3. Different ways of visualizing cells and the collagen network. (a) 24-36 h after LPS stimulation, mature dendritic cells are non-adherent and show prominent protrusions ("veils"). (b) Cells and collagen fibers are visualized by differential interference contrast (DIC) microscopy. (c and d) Merged confocal stacks of fibrillar collagen networks obtained by reflection microscopy. Cells might also give a signal by reflection (small round circles in c). (e and f) Merged confocal stacks of fluorescent collagen networks. If collagen (e) and cells (f) are differentially fluorescently labeled, they can clearly be distinguished and separated. We courteously thank Dr. Caren Petri Aronin for kindly providing Fig. 3e and f.

\section{Table 3}

\section{Pros and cons for different ways of visualizing the collagen network}

\begin{tabular}{|c|c|c|}
\hline & Pros & Cons \\
\hline $\begin{array}{l}\text { Differential interfer- } \\
\text { ence contrast (DIC) } \\
\text { (Bright-field } \\
\text { microscopy) }\end{array}$ & $\begin{array}{l}\text { - no collagen labeling required } \\
\text { - requires only DIC objective }\end{array}$ & $\begin{array}{l}\text { - collagen fibers only visualized in one } \\
\text { plane of focus } \\
\text { - topographically inaccurate }\end{array}$ \\
\hline $\begin{array}{l}\text { Reflection (confocal } \\
\text { microscopy) }\end{array}$ & $\begin{array}{l}\text { - no collagen labeling required } \\
\text { - requires only laser scanning } \\
\text { confocal microscope }\end{array}$ & $\begin{array}{l}\text { - can produce reflection of the cells as } \\
\text { well } \\
\text { - requires high laser power } \\
\text { - not suitable for spinning-disc confocal } \\
\text { microscopy }\end{array}$ \\
\hline $\begin{array}{l}\text { Fluorescence (confocal } \\
\text { microscopy) }\end{array}$ & $\begin{array}{l}\text { - suitable for spinning-disc } \\
\text { confocal microscopy } \\
\text { - requires only low laser power }\end{array}$ & $\begin{array}{l}\text { - requires fluorescent collagen } \\
\text { - varying degrees of photobleaching of } \\
\text { the fluorescent collagen over time }\end{array}$ \\
\hline
\end{tabular}

Alexa Fluor 647 reactive dye to the stirred Purecol $^{\circledR}$. Then, continue stirring in the dark for $48 \mathrm{~h}$ at $4^{\circ} \mathrm{C}$. After labeling, free dye molecules have to be removed by dialysis.

3. Prepare 3.5 in. of dialysis tubing, pre-soak it for $20 \mathrm{~min}$ in distilled water, and then rinse it thoroughly with clean distilled 
water. Set one clamp 1 in. apart from the bottom side of the tubing.

4. Fill the $10 \mathrm{~mL}$ acidic, dye-labeled collagen solution into the tubing and place the second clamp at the other side to form a not too tightly packed, closed dialysis bag in the middle of the tubing.

5. Place the dialysis bag in a large beaker with $1 \mathrm{~L}$ acetic acid and slowly stir for 1 week at $4^{\circ} \mathrm{C}$ in the dark. Try to prevent the dialysis bag touching the stir bar by fixing it at the upper part of the beaker. Keep the Alexa Fluor 647-labeled collagen solution at $4^{\circ} \mathrm{C}$ until use.

6. To generate fluorescent collagen gels, we recommend mixing Alexa Fluor 647-labeled collagen with unlabeled collagen in a 1:20 ratio for the collagen-mix (see Subheading 3.5).

\section{Notes}

1. Dendritic cells with a high migratory potential are morphologically characterized by (1) loss of adhesion to the tissue-cell culture plastic 24-36 h after LPS stimulation and (2) prominent cell protrusions ("veils") all over the cell body. We and other investigators have observed that this phenomenon is highly dependent on the batch or lot of FCS/FBS used in the R10 medium. Since the composition of serum varies between manufacturers and between batches, we recommend an initial assessment of the effect of different sera on DC maturation. This can be achieved by flow cytometric assessment of surface activation markers (such as MHCII, CD86, CD80, and CD40), although the presence of such markers does not completely guarantee that the mature dendritic cells will have a high migratory potential.

2. Incubating immature dendritic cells at days 8-9 of culture with LPS is only one way to acquire migratory DCs. Alternatively, other stimuli such as $500 \mathrm{U} / \mathrm{mL}$ TNF- $\alpha$ can be used (19).

3. We have used Purecol ${ }^{\circledR}$ and Nutragen ${ }^{\circledR}(2,8)$, but bovine collagen preparations are also provided by other manufacturers.

4. Petroleum jelly will make the paraffin more fluid and easier to brush. You may wish to test the paraffin mixture by brushing it onto a test glass slide.

5. Commercially available glass-bottomed microscopy dishes (e.g., MatTek) can be used as an alternative to glass slides. These dishes already have some spacing between the glassbottom and cell culture plastic, and you can skip step 2 . This approach is probably less time consuming, but more expensive. If you are doing confocal microscopy or differential interference 
contrast microscopy (requiring imaging through a No. 1.5 glass slide), then it is helpful to assess which setup approach will be otimal for your specific microscope (upright or inverted light path) and microscopy stage.

6. Start with a cell suspension at a concentration of $3 \times 10^{6}$ cells/ $\mathrm{mL}$ (this will provide approximately 100,000 cells per one standard migration chamber). This cell number is optimal for bright-field imaging at low magnification $(10 \times$ to $20 \times$ objectives) when cells of different focal planes are visualized simultaneously (see Note 17). In contrast to dendritic cells (with a cell diameter $>10 \mu \mathrm{m}$ ), collagen gels with smaller cells (granulocytes and lymphocytes) will require higher cell concentrations $\left(5-6 \times 10^{6}\right.$ cells $\left./ \mathrm{mL}\right)$ to ensure sufficient cell numbers in the field of view during microscopy (2). For confocal microscopy, you may also want to increase the cell concentration when you are only imaging in single planes of focus.

7. Bone marrow-derived dendritic cells are pretty robust and can also be kept at $4^{\circ} \mathrm{C}$ (or on ice) for up to $1-2 \mathrm{~h}$ without losing migratory potential.

8. A larger tip opening reduces the likelihood of air bubbles produced while pipetting the viscous collagen. Depending on the number of assays you are preparing, you will either choose $20-200-\mu \mathrm{L}$ or $200-1,000-\mu \mathrm{L}$ tips.

9. As the extracted bovine collagen is only soluble after acidification, the addition of sodium bicarbonate is required to bring the $\mathrm{pH}$ to physiological levels (4). When pipetting collagen, add MEM (10x) first, followed by sodium bicarbonate (the color of the mix will change from yellow to orange-red, indicating $\mathrm{pH}$ change). The collagen mix will stay soluble at room temperature and only polymerize at $37^{\circ} \mathrm{C}$.

10. Tables 1 and 2 give pipetting schemes for collagen gels of different concentrations resulting in different pore-sized collagen networks. For higher collagen concentrations, you will have to use Nutragen ${ }^{\circledR}$ (stock concentration: $6 \mathrm{mg} / \mathrm{mL}$ ) instead of Purecol $^{\circledR}$ (stock concentration: $3 \mathrm{mg} / \mathrm{mL}$ ). The table also accounts for various numbers of samples to be prepared.

11. If using irreversible small chemical inhibitors (2), these can be added at this step of the collagen gel procedure in order to have the inhibitor continuously present in the migration assay.

12. The even horizontal lining of the collagen-gel mix will later define the border between polymerized collagen gel and soluble chemokine solution. It very much depends on the initial thickness of the paraffin line when constructing the migration chamber (see Subheading 3.2, step 2). If the paraffin lining is too thin, then capillary forces will counteract the gravity-induced 
fall of the viscous collagen-gel mix. If the paraffin lining is too thick, cells will be visualized in too many planes of focus by bright-field microscopy, which may cause problems during the final migration analysis (see Note 17). Please also bear in mind that the final microscopic field of view is only a small portion of the entire migration chamber.

13. In contrast to rat-tail collagen that polymerizes within few minutes, the polymerization of bovine collagen gels takes approximately $30 \mathrm{~min}$ at $37^{\circ} \mathrm{C}$. As cells in the collagen-cell mix can still "fall" by gravity, it is therefore essential to keep the migration chamber in an upright position during gel polymerization. This ensures that cells will be distributed in all different planes of focus of the collagen gel. Otherwise, $30 \mathrm{~min}$ is sufficient time for the cells to "fall" to the bottom glass side of a 1-mm-thick migration chamber. Occasionally, the collagen-gel mixture does not fully polymerize within $30 \mathrm{~min}$ and takes up to $1 \mathrm{~h}$. This problem can be resolved by increasing the $\mathrm{pH}$ of the sodium bicarbonate solution $(\mathrm{pH}$ 7.5-7.9) (as happens when leaving an aliquot of sodium bicarbonate open to the air).

14. The 3D collagen gel system described here has been successfully used for visualizing defined chemotactic responses of murine dendritic cells, neutrophils, and activated lymphoblasts. As this setup is a closed system, the gas exchange with the surrounding might be limited and some cell types that are very sensitive to oxygen supply or nutrient flow (e.g., naïve $\mathrm{T}$ cells) might not migrate under these conditions (20).

15. In principle, this $3 \mathrm{D}$ chemotaxis assay is applicable to every possible chemotactic cell type. Random cell migration in $3 \mathrm{D}$ collagen gels has been shown in numerous studies with cells of low-adhesive (e.g., leukocytes) to highly adhesive (e.g., fibroblasts and endothelial cells. This assay might be useful for the study of their specific chemotactic responses to cytokines, chemokines, or growth factors. However, the experimental conditions (e.g., chemokine concentration and duration of migration) might vary depending on the relevant cell typechemokine combination and will require individual testing. Parameters such as chemokine diffusion, receptor desensitization, cellular activation, and adhesiveness are only a few of the factors that might affect the quality of the chemotactic response. The 3D chemotaxis system described here does not allow exact manipulation of the chemokine gradient, but more complicated setups have been described which allow more precise determination of such parameters (21).

16. The image acquisition time should be chosen according to the expected speed of the cell. As examples, we suggest for fast migrating cells (e.g., neutrophils and lymphoblasts, 
10-15 $\mu \mathrm{m} / \mathrm{min})$ one frame per every $15-30 \mathrm{~s}$, for dendritic cells $(3-5 \mu \mathrm{m} / \mathrm{min})$ one frame per $1-2 \mathrm{~min}$, and fibroblasts $(1-5 \mu \mathrm{m} / \mathrm{h})$ one frame per $5 \mathrm{~min}$.

17. When acquired with bright-field microscopy, time-lapse video sequences of 3D collagen gels will finally result in a series of 2D images with cells in different planes of focus. Although the manual tracking is actually $2 \mathrm{D}$ tracking and underestimates cell movement in the $z$-axis, this method gives a good representation of the actual cell velocities and directionality as the chemotactic gradient defines migration in the $X-\Upsilon$ plane. More sophisticated, commercially available image analysis software and custom-made solutions ( $P$. Friedl, personal communication) allow automated tracking or analysis of migration in $X-\Upsilon-Z$ dimensions.

18. For more detailed information on experimental setups and requirements of differential interference microscopy (2), reflection microscopy (4), and spinning disc confocal microscopy (9), we refer to published data.

19. We would like to thank Dr. Caren Petri Aronin (NIAID, NIH, Bethesda, USA) and Prof. Matthias Gunzer (University of Magdeburg, Germany) for providing protocols and sharing technical expertise on the described methods. We would also like to thank Dr. Menna Clatworthy (NIAID, NIH, Bethesda, USA) for critical reading of the manuscript.

\section{References}

1. Cukierman, E., Pankov, R., Stevens, D. R., and Yamada, K. M. (2001) Taking cell-matrix adhesions to the third dimension, Science (New York, N.Y 294, 1708-1712.

2. Lämmermann, T., Bader, B. L., Monkley, S. J., Worbs, T., Wedlich-Soldner, R., Hirsch, K., Keller, M., Forster, R., Critchley, D. R., Fassler, R., and Sixt, M. (2008) Rapid leukocyte migration by integrin-independent flowing and squeezing, Nature 453, 51-55.

3. Martin-Belmonte, F., and Mostov, K. (2008) Regulation of cell polarity during epithelial morphogenesis, Current opinion in cell biology 20, 227-234.

4. Wolf, K., Alexander, S., Schacht, V., Coussens, L. M., von Andrian, U. H., van Rheenen, J., Deryugina, E., and Friedl, P. (2009) Collagenbased cell migration models in vitro and in vivo, Seminars in cell \& developmental biology 20, 931-941.

5. Wolf, K., Mazo, I., Leung, H., Engelke, K., von Andrian, U. H., Deryugina, E. I., Strongin, A. Y., Brocker, E. B., and Friedl, P. (2003) Compensation mechanism in tumor cell migration: mesenchymal-amoeboid transition after blocking of pericellular proteolysis, The Journal of cell biology 160, 267-277.

6. Yamada, K. M., and Cukierman, E. (2007) Modeling tissue morphogenesis and cancer in 3D, Cell 130, 601-610.

7. Reichardt, P., Gunzer, F., and Gunzer, M. (2007) Analyzing the physicodynamics of immune cells in a three-dimensional collagen matrix, Methods in molecular biology (Clifton, NJ) 380, 253-269.

8. Lämmermann, T., Renkawitz, J., Wu, X., Hirsch, K., Brakebusch, C., and Sixt, M. (2009) Cdc42-dependent leading edge coordination is essential for interstitial dendritic cell migration, Blood 113, 5703-5710.

9. Lämmermann, T., and Sixt, M. (2009) Mechanical modes of "amoeboid" cell migration, Current opinion in cell biology 21, 636-644.

10. Schmidt, S., and Friedl, P. (2010) Interstitial cell migration: integrin-dependent and alternative adhesion mechanisms, Cell and tissue research 339, 83-92. 
11. Sabeh, F., Shimizu-Hirota, R., and Weiss, S. J. (2009) Protease-dependent versus -independent cancer cell invasion programs: threedimensional amoeboid movement revisited, The Journal of cell biology 185, 11-19.

12. Peters, N. C., Egen, J. G., Secundino, N., Debrabant, A., Kimblin, N., Kamhawi, S., Lawyer, P., Fay, M. P., Germain, R. N., and Sacks, D. (2008) In vivo imaging reveals an essential role for neutrophils in leishmaniasis transmitted by sand flies, Science (New York, N.r 321, 970-974.

13. Pflicke, H., and Sixt, M. (2009) Preformed portals facilitate dendritic cell entry into afferent lymphatic vessels, The Journal of experimental medicine 206, 2925-2935.

14. Shields, J. D., Fleury, M. E., Yong, C., Tomei, A. A., Randolph, G. J., and Swartz, M. A. (2007) Autologous chemotaxis as a mechanism of tumor cell homing to lymphatics via interstitial flow and autocrine CCR7 signaling, Cancer cell 11, 526-538.

15. Quast, T., Tappertzhofen, B., Schild, C., Grell, J., Czeloth, N., Forster, R., Alon, R., Fraemohs, L., Dreck, K., Weber, C., Lämmermann, T., Sixt, M., and Kolanus, W. (2009) Cytohesin-1 controls the activation of RhoA and modulates integrin-dependent adhesion and migration of dendritic cells, Blood 113, 5801-5810.

16. Brightman, A. O., Rajwa, B. P., Sturgis, J. E., McCallister, M. E., Robinson, J. P., and VoytikHarbin, S. L. (2000) Time-lapse confocal reflection microscopy of collagen fibrillogenesis and extracellular matrix assembly in vitro, Biopolymers 54, 222-234.

17. Bonvin, C., Overney, J., Shieh, A. C., Dixon, J. B., and Swartz, M. A. (2010) A multichamber fluidic device for 3D cultures under interstitial flow with live imaging: development, characterization, and applications, Biotechnology and bioengineering 105, 982-991.

18. Lutz, M. B., Kukutsch, N., Ogilvie, A. L., Rossner, S., Koch, F., Romani, N., and Schuler, G. (1999) An advanced culture method for generating large quantities of highly pure dendritic cells from mouse bone marrow, Journal of immunological methods 223, 77-92.

19. Menges, M., Rossner, S., Voigtlander, C., Schindler, H., Kukutsch, N. A., Bogdan, C., Erb, K., Schuler, G., and Lutz, M. B. (2002) Repetitive injections of dendritic cells matured with tumor necrosis factor alpha induce antigen-specific protection of mice from autoimmunity, The Journal of experimental medicine $195,15-21$.

20. Huang, J. H., Cardenas-Navia, L. I., Caldwell, C. C., Plumb, T. J., Radu, C. G., Rocha, P. N., Wilder, T., Bromberg, J. S., Cronstein, B. N., Sitkovsky, M., Dewhirst, M. W., and Dustin, M. L. (2007) Require-ments for T lymphocyte migration in explanted lymph nodes, J Immunol 178, 7747-7755.

21. Haessler, U., Kalinin, Y., Swartz, M. A., and Wu, M. (2009) An agarose-based microfluidic platform with a gradient buffer for 3D chemotaxis studies, Biomedical microdevices 11 , 827-835. 